Copyright (C) 2017 by Academic Publishing House Researcher

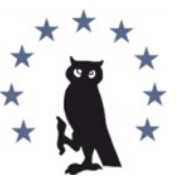

Published in the Russian Federation

European Researcher. Series A

Has been issued since 2010.

ISSN 2219-8229

E-ISSN 2224-0136

2017, 8(4): 321-328

DOI: 10.13187/er.2017.4.321

www.erjournal.ru

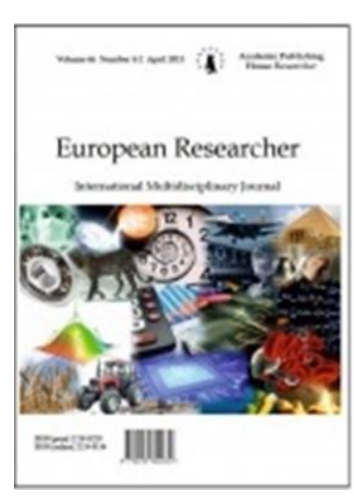

UDC 37

\title{
The Specificity of Psychological and Pedagogical Support of Children with Signs of Giftedness in Organization of Additional Education
}

Salahidin U. Tursunbaev ${ }^{a},{ }^{*}$, Evgenia A. Kalina a

a Creativity and Humanitarian Education Center in Sochi, Municipal Educational Budgetary Institution of Further Education for Children, Russian Federation

\begin{abstract}
The article discusses the importance of creating and ensuring the psycho-pedagogical terms of support for gifted children. The article presents the peculiarities of psychological and pedagogical support of children with signs of giftedness in terms of organization of further education, based on the analysis of scientific-methodical literature and pedagogical practice of studying. It summarizes the experience of psycho-pedagogical support of children with signs of giftedness in Sochi center of creative development and humanitarian education.

Keywords: gifted children, children with signs of giftedness, psychological and pedagogical support of gifted children, organization of additional education of children.

\section{1. Введение}

В настоящее время создание условий, обеспечивающих эффективность выявления и развития одаренных детей, реализацию их потенциальных возможностей, является одной из ведущих задач современного общества, а наличие социального заказа способствует интенсивному росту научно-исследовательских и прикладных работ в этой области (Голубева, 2005).

Анализ современных образовательных практик показывает, что одним из эффективных условий выявления и развития одаренных детей является развитие системы их сопровождения. Но, несмотря на объективно существующий опыт работы с одаренными детьми, в современных исследованиях недостаточно изучены подходы к обеспечению психолого-педагогического сопровождения обучающихся с признаками одаренности в системе дополнительного образования. Практика такого сопровождения чаще всего фрагментарна и не лишена недостатков, поскольку в ряде случаев строится без учета специфики организаций дополнительного образования.

Основной целью исследования, результаты которого представлены в статье, является выявление особенностей психолого-педагогического сопровождения детей с признаками одаренности в условиях организации дополнительного образования.
\end{abstract}

\footnotetext{
${ }^{*}$ Corresponding author

E-mail addresses: sashaum@mail.ru (S.U.Tursunbaev), evgeniya_dubchen@mail.ru (E.A. Kalina)
} 


\section{2. Материалы и методы}

Материалом исследования стала психолого-педагогическая литература, в которой описываются современные модели сопровождения одаренных обучающихся в организациях дополнительного образования, а методами исследования - анализ теоретических источников, анализ и обобщение опыта работы с одаренными детьми, методы систематизации и классификации материалов.

\section{3. Обсуждение}

В настоящее время социальный заказ требует от системы дополнительного образования детей направленности образовательных программ на психологопедагогическое сопровождение одаренных обучающихся и поиска приоритетных направлений развития их интеллектуально-творческого потенциала.

Рядом исследователей (Леонтович, 2011; Белоусова и др., 2016; Савенков, 2010; Толстопятова, 2004; Богоявленская и др., 2003; Neskoromnykh et al., 2017; Нескоромных, Мамадалиев, 2017 и др.) дополнительное образование признается важнейшей сферой для развития детей с признаками одаренности в силу личностно-деятельностного характера образовательного процесса; свободного выбора детьми образовательной области, профиля программ, времени их освоения, включения в разнообразные виды деятельности с учетом их познавательных потребностей; вариативности образования, отсутствия образовательных стандартов и жестко определенных государственных образовательных программ по соответствующему предмету (направленности). Процесс обучения носит более неформальный характер, потому он ближе к природе интеллектуального и творческого развития одаренных детей.

Дополнительное образование обладает психотерапевтическими возможностями (Сафронова, 2010): возможностями для индивидуального развития у детей тех способностей, которые не всегда получают поддержку в системе общего образования; возможностями для детей, занимаясь различными видами деятельности в соответствии с личными интересами, включаться в диалог с педагогом и переживать ситуации успеха.

\section{4. Результаты исследования}

В отечественной системе дополнительного образования получили распространение такие формы обучения одаренных детей и детей $\mathrm{c}$ признаками одаренности: 1) индивидуальное и групповое обучение по программам творческого развития в определенной области; 2) работа по исследовательским и творческим проектам в режиме наставничества; 3) очно-заочные школы; 4) каникулярные сборы, лагеря, мастер-классы, творческие лаборатории; 5) творческие конкурсы, фестивали, олимпиады; 6) детские научно-практические конференции, семинары.

В организациях дополнительного образования, также, как и в организациях общего образования, реализуются 4 стратегии обучения одаренных детей: ускорение, обогащение, углубление, проблематизация (Богоявленская и др., 2003).

Организация психолого-педагогического сопровождения детей с признаками одаренности в организации дополнительного образования отличается от сопровождения в других образовательных организациях и имеет особенности:

- сопровождение детей наряду с воспитанием и обучением является составной частью системы дополнительного образования, решающей проблемы использования свободного времени детей для их интеллектуального и личностного развития; реализации и развития детской одаренности;

- поскольку дополнительное образование является непрерывным процессом, то и сопровождение детей тоже не имеет фиксированных сроков завершения и последовательно переходит из одной стадии в другую;

- в деятельности организаций дополнительного образования по сопровождению детей с признаками одаренности выделяются общие элементы: 1) диагностика на этапе отбора детей для занятий по образовательной программе, на начальном и заключительном этапах реализации образовательной программы, в проблемных ситуациях для выделения группы риска; 2) проектирование и реализация программ сопровождения детей с гармоничным 
типом одаренности; 3) проектирование и реализация программ сопровождения детей с дисгармоничным типом одаренности;

- деятельность педагога-психолога и педагогов в рамках сопровождения направлена на обеспечение эффективности двух согласованных процессов: индивидуального сопровождения и группового, направленного на профилактику и/или преодоление потенциальных и актуальных проблем, характерных не для одного ребенка, а для группы детей;

- обеспечивается непрерывность сопровождения развития детей по вертикали (выстраивается преемственность в обучении на разных возрастных этапах развития детей) и по горизонтали (обеспечивается интеграция различных образовательных программ на определенном этапе развития);

- идентификация детей с признаками одаренности осуществляется через систему конкурсов, олимпиад, научно-практических конференций;

- проводится мониторинг динамики достижений детей;

- психолого-педагогическое сопровождение охватывает зоны риска возникновения дефицитов развития одаренных детей (асинхронии развития) различных сфер личности: когнитивной, регуляторно-волевой, аффективно-эмоциональной, коммуникативной.

Эти особенности характерны и для системы психолого-педагогического сопровождения детей с признаками одаренности в муниципальном образовательном бюджетном учреждении дополнительного образования «Центр творческого развития и гуманитарного образования» города Сочи (далее - Центр). Выделим ряд концептуальных положений, лежащих в основе функционирования этого Центра:

1. Целью функционирования Центра является создание условий для гармоничного и разностороннего интеллектуального развития личности обучающихся, реализации их интеллектуальных и творческих способностей в учебной, проектной и исследовательской деятельности, что обеспечивается системой взаимодействия с организациями общего образования.

2. В Центре создана инновационная образовательная среда, позволяющая обеспечить личностное развитие, самореализацию обучающихся за счет реализации разработанной модели инновационной среды на принципах сетевого взаимодействия и социального партнерства (с ООО «БИНОМ лаборатория знаний», ЦДО «Президентская школа» г. Москва, ГБОУ ДОД ЦДОДД г. Краснодар, Российской ассоциацией образовательной робототехники, программой «Робототехника: инженерно-технические кадры инновационной России», компанией LEGO Education, компанией «КиберТех», компанией «Samsung», Международным общественным фондом культуры и образования, ФГАОУ ВО «Московский физико-технический институт (государственный университет)», ФГБОУ ВО «Московский технологический университет», ФГБОУ ВО «Российский государственный педагогический университет им. А.И. Герцена», ФГБОУ ВО «Сочинский государственный университет» и др.); реализован кластерный подход к построению образовательного пространства, включая совместную разработку образовательных программ, социокультурных практик и образовательных взаимодействий.

3. Психолого-педагогическое сопровождение детей осуществляется отделом диагностики и психологического сопровождения на основе гуманистического, аксиологического, личностно-ориентированного, полисубъектного подходов; выстраивается как целостная система диагностических, развивающих, коррекционных, профилактических средств, составляющих инвариантный (базовый) и вариативный (специальный) компоненты.

4. Психолого-педагогическое сопровождение детей с признаками одаренности выстроено как система их поддержки и помощи в решении задач развития, обучения, социализации в условиях реализующихся образовательных программ.

Модель инновационной образовательной среды личностного развития и самореализации детей с признаками одаренности в Центре представлена на рис. 1. 


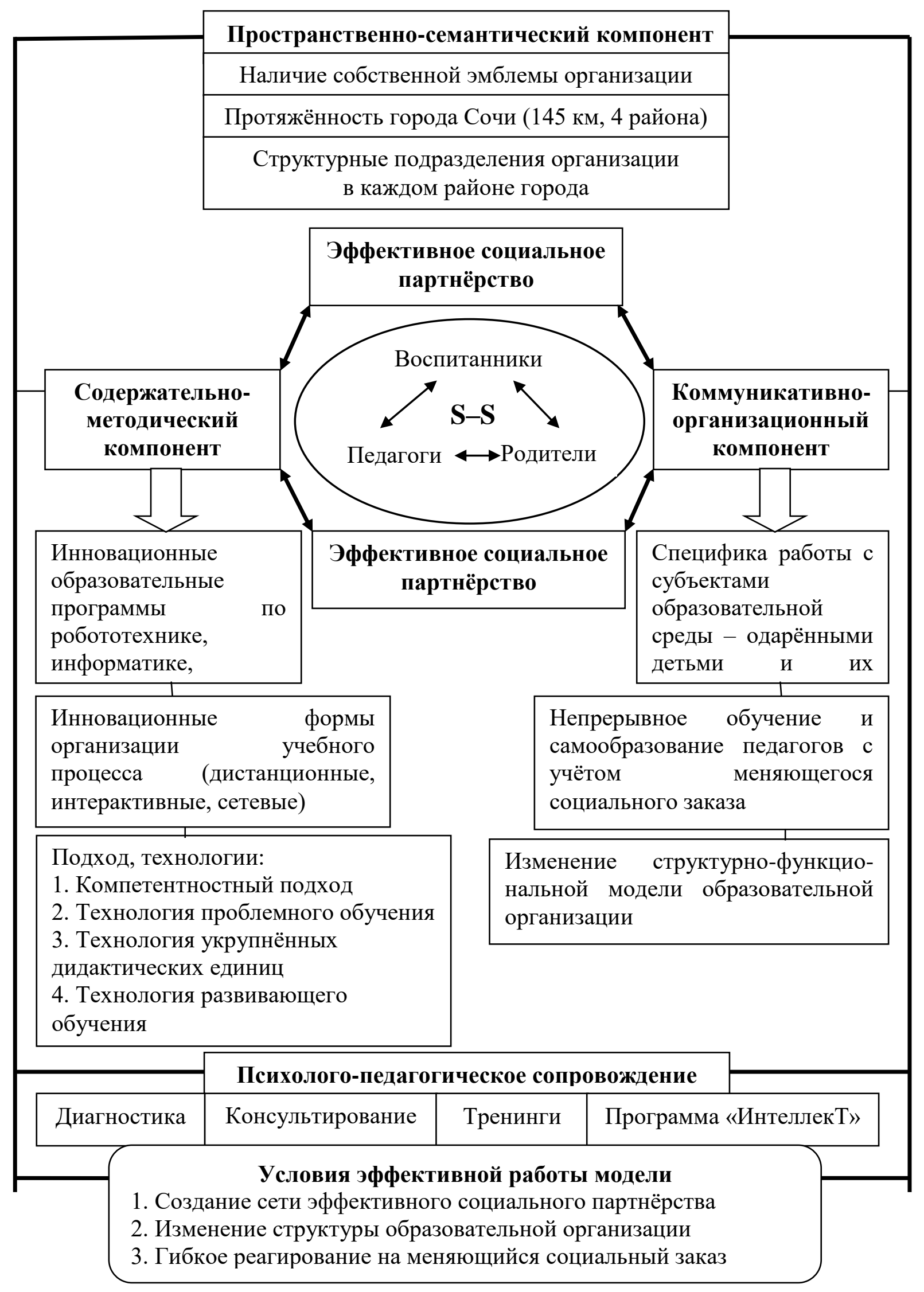

Рис. 1. Модель инновационной образовательной среды личностного развития и самореализации обучающихся с признаками одаренности в Центре творческого развития и гуманитарного образования 
В центре модели - субъект-субъектные отношения в образовательной среде (обучающихся, педагогов, родителей). На субъекты образовательной среды непосредственно (контактно) или опосредованно (с помощью информационно-коммуникационных технологий) воздействуют остальные элементы системы; на них направлены все предполагаемые инновационные изменения. Ключевой механизм взаимодействия эффективное социальное партнерство - задает векторы развития и взаимодействия трем компонентам:

1) пространственно-семантическому, включающему внешние культурно-эстетические аспекты: особенности обустройства помещений, ключевую стендовую информацию и специфику ее оформления, геральдическую трактовку эмблемы и территориальные особенности города Сочи (4 административных района общей протяженностью 145 км), важные для внедрения инновации;

2) содержательно-методическому, включающему основные понятия, направления и процессы: выделенные из основной (общей) образовательной программы Центра предметные направления технического и естественно-научного цикла: «Робототехника» (инновационное направление), «Информатика», «Математика», «Химия», «Физика» (инновация состоит в новых для учреждения формах обучения: дистанционные и сетевые), подходы, технологии и методики, приведенные на рис. 1;

3) коммуникативно-организационному, включающему процессы, связанные со спецификой работы с субъектами: особенности педагогического взаимодействия в работе с детьми и их родителями, непрерывное повышение квалификации и самообразование педагогов с учетом социального заказа; изменение процессов управления учреждением через изменение его структурно-функциональной модели (появление структурных подразделений в каждом районе города).

В Центре созданы условия для развития детей с признаками интеллектуальной одаренности:

1) разработаны научно обоснованные образовательные программы, имеются положительные результаты их реализации;

2) разработана и построена система выявления детей с признаками интеллектуальной одаренности;

3) образовательный процесс проектируют и осуществляют квалифицированные педагоги, готовые к работе с одаренными детьми;

4) выстроена система обратной связи, позволяющая отслеживать эффективность функционирования Центра и появление нежелательных отклонений в его работе (в том числе подсистема «Психолого-педагогический мониторинг обучающихся»);

5) в основу работы Центра положены принципы добровольности (обеспечен свободный выбор детьми образовательных программ) и гибкости (обеспечено «вхождение» детей в образовательные программы и «нестрессовый выход из них на любом этапе); 6) обеспечено бесплатное обучение детей с признаками одаренности (Соответствующие требования сформулированы в работе (Толстопятова, 2004: 73-74).

Образовательные программы для детей с признаками интеллектуальной одаренности, реализуемые в Центре, отвечают требованиям, сформулированным отечественными учеными (Ю.Д. Бабаевой, Д.Б. Богоявленской, А.В. Брушлинским, В.Н. Дружининым, И.И. Ильясовым, Н.С. Лейтесом, А.М. Матюшкиным, А.И. Савенковым, М.А. Холодной, В.Д. Шадриковым, Н.Б. Шумаковой, В.С. Юркевич и др.). С учетом этих требований отобраны, разработаны и реализуются в Центре образовательные программы:

1) включающие изучение широких тем и проблем, что позволяет учитывать интерес детей к универсальному и общему, их повышенное стремление к обобщению, теоретическую ориентацию и интерес к будущему;

2) предусматривающие в обучении междисциплинарный подход на основе интеграции тем и проблем, относящихся к различным областям знания, что позволяет стимулировать стремление одаренных детей к расширению и углублению знаний, развивать их способности к соотнесению разнородных явлений и поиску решений на «стыке» разных типов знаний;

3) предполагающие изучение проблем «открытого типа», позволяющих учитывать склонность детей к исследовательскому типу поведения, формировать навыки и методы исследовательской работы; 
4) в максимальной мере учитывающие интересы одаренных детей и поощряющие углубленное изучение того, что выбрано ими самими;

5) поддерживающие и развивающие самостоятельность в учении;

6) обеспечивающие гибкость и вариативность учебного процесса с точки зрения содержания, форм и методов обучения;

7) предусматривающие наличие и свободное использование разнообразных источников и способов получения информации (в том числе через компьютерные сети);

8) включающие качественное изменение учебной ситуации и учебного материала (в том числе подготовку специальных учебных пособий, специализированные учебные кабинеты);

9) предусматривающие обучение детей критериальному оцениванию результатов своей работы, формированию у них навыков публичного обсуждения и отстаивания своих идей и итогов творчества;

10) способствующие развитию самопознания, пониманию индивидуальных особенностей других людей;

11) включающие элементы психологической поддержки и помощи с учетом своеобразия личности каждого ребенка с признаками одаренности (требования, которым удовлетворяют образовательные программы, сформулированы в работе (Толстопятова, 2004: 74-75).

Программы, реализуемые в Центре, готовят обучающихся к выстраиванию успешных индивидуальных образовательных траекторий. Об этом свидетельствуют достижения воспитанников Центра, большинство из которых являются неоднократными победителями, лауреатами Всероссийского конкурса исследовательских работ им. В.И. Вернадского, Российского конкурса исследовательских работ и творческих проектов дошкольников и младших школьников «Я - исследователь», Российского конкурса молодых исследователей «Шаг в будущее», Молодежного экологического форума «ЮНЭКО», краевой научнопрактической конференции Малой Академии наук учащихся Кубани «Эврика», городской научно-практической конференции «Первые шаги в науку».

В то же время проблемный анализ системы психолого-педагогического сопровождения детей с признаками одаренности в Центре выявил ряд актуальных проблем педагогов (рассогласование деятельности специалистов службы сопровождения и педагогов; отсутствие необходимых системности и комплексности работы по сопровождению обучающихся и др.), решение которых будет способствовать развитию интеллектуального и творческого потенциала, формированию образовательной индивидуальности обучающихся, гармоничного типа одаренности личности. Решить выявленные проблемы можно за счет разработки и реализации новой модели процесса психолого-педагогического с сопровождения детей с признаками одаренности в условиях организации дополнительного образования (непротиворечивой, построенной с учетом современных исследований проблемы детской одаренности и проблемы сопровождения развития одаренных детей, с учетом специфики организации дополнительного образования детей).

\section{5. Заключение}

Выявленные особенности психолого-педагогического сопровождения детей с признаками одаренности в организации дополнительного образования будут полезны при теоретической, экспериментальной и методической проработке системы многоуровневой и многофункциональной обогащенной образовательной среды для развития одаренных детей.

\section{Литература}

Белоусова и др., 2016 - Белоусова Т.Н., Мамадалиев А.М., Черединов С.Ю. Моделирование тьюторской деятельностив условиях учреждения дополнительного образования: теоретические аспекты // Веснік Віцебскага дзяржаўнага універсітэта. 2016. № 3 (92). C. 58-64.

Голубева, 2005 - Голубева Э.А. Способности. Личность. Индивидуальность. Дубна: Феникс+, 2005. 512 с. 
Леонтович, 2011 - Леонтович А.В. Организация содержательной деятельности учреждения дополнительного образования детей. М.: Московский городской дворец детского (юношеского) творчества, 2011. 230 с.

Нескоромных, Мамадалиев, 2017 - Нескоромных Н.И., Мамадалиев А.М. Стратегии адаптивного поведения лиц пожилого возраста в интернет-пространстве // Медиаобразование. 2017. № 1. С. 163-175.

Савенков, 2010 - Савенков А.И. Психология детской одаренности. М.: Генезис, 2010. $448 \mathrm{c}$.

Толстопятова, 2004 - Толстопятова O.A. Психолого-педагогическое сопровождение обучения и развития интеллектуально-одаренных детей в условиях организации дополнительного общего образования: дис. ... канд. пед. наук. Ставрополь, 2004. 171 с.

Богоявленская и др., 2003 - Богоявленская Д.Б. и др. Рабочая концепция одаренности. М.: Министерство образования РФ. Федеральная целевая программа «Одаренные дети», 2003. 95 c.

Сафронова, 2010 - Сафронова Т.Г. Взаимодействие основного и дополнительного образования: развитие творческой одаренности личности // Одаренный ребенок. 2010. № 3 . C. 101-105.

Neskoromnykh et al., 2017 - Neskoromnykh N.I., Chernenko N.V., Mamadaliev A.M., Vorozhbitova A.A. Educational-Cognitive Barriers in the Preparation of Future Social Pedagogues for the Prevention of Social Dependencies // European Journal of Contemporary Education, 2017, 6(1): 57-63.

\section{References}

Belousova i dr., 2016 - Belousova T.N., Mamadaliev A.M., Cheredinov S.Yu. (2016). Modelirovanie t'yutorskoi deyatel'nostiv usloviyakh uchrezhdeniya dopolnitel'nogo obrazovaniya: teoreticheskie aspekty. Vesnik Vitsebskaga dzyarzhay̆naga universiteta. № 3 (92). pp. 58-64.

Golubeva, 2005 - Golubeva E.A. (2005). Sposobnosti. Lichnost'. Individual'nost'. Dubna: Feniks+. $512 \mathrm{p}$.

Leontovich, 2011 - Leontovich A.V. (2011). Organizatsiya soderzhatel'noi deyatel'nosti uchrezhdeniya dopolnitel'nogo obrazovaniya detei. M.: Moskovskii gorodskoi dvorets detskogo (yunosheskogo) tvorchestva. $230 \mathrm{p}$.

Neskoromnykh, Mamadaliev, 2017 - Neskoromnykh N.I., Mamadaliev A.M. (2017). Strategii adaptivnogo povedeniya lits pozhilogo vozrasta v internet-prostranstve. Mediaobrazovanie. № 1 . pp. $163-175$.

Savenkov, 2010 - Savenkov A.I. (2010). Psikhologiya detskoi odarennosti. M.: Genezis. $448 \mathrm{p}$.

Tolstopyatova, 2004 - Tolstopyatova O.A. (2004). Psikhologo-pedagogicheskoe soprovozhdenie obucheniya i razvitiya intellektual'no-odarennykh detei v usloviyakh organizatsii dopolnitel'nogo obshchego obrazovaniya: dis. ... kand. ped. nauk. Stavropol'. 171 p.

Bogoyavlenskaya i dr., 2003 - Bogoyavlenskaya D.B. $i$ dr. (2003). Rabochaya kontseptsiya odarennosti. M.: Ministerstvo obrazovaniya RF. Federal'naya tselevaya programma «Odarennye deti». $95 \mathrm{p}$.

Safronova, 2010 - Safronova T.G. (2010). Vzaimodeistvie osnovnogo i dopolnitel'nogo obrazovaniya: razvitie tvorcheskoi odarennosti lichnosti. Odarennyi rebenok. № 3. pp. 101-105.

Neskoromnykh et al., 2017 - Neskoromnykh N.I., Chernenko N.V., Mamadaliev A.M., Vorozhbitova A.A. (2017). Educational-Cognitive Barriers in the Preparation of Future Social Pedagogues for the Prevention of Social Dependencies. European Journal of Contemporary Education, 6(1): 57-63. 
УДК 37

\section{Специфика психолого-педагогического сопровождения детей с признаками одаренности в организации дополнительного образования}

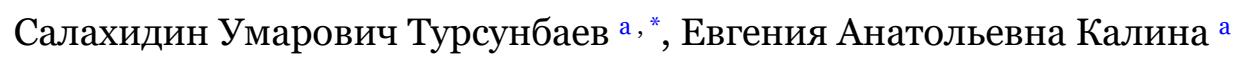

${ }^{\text {a } Ц е н т р ~ т в о р ч е с к о г о ~ р а з в и т и я ~ и ~ г у м а н и т а р н о г о ~ о б р а з о в а н и я ~ г . ~ С о ч и, ~ Р о с с и и ̆ с к а я ~ Ф е д е р а ц и я ~}$

Аннотация. В статье рассматривается значимость создания и обеспечения психологопедагогических условий сопровождения одаренных детей. На основе анализа научнометодической литературы и изучения педагогической практики раскрываются особенности психолого-педагогического сопровождения детей с признаками одаренности в условиях организации дополнительного образования. Обобщен опыт психолого-педагогического сопровождения детей с признаками одаренности в Сочинском центре творческого развития и гуманитарного образования.

Ключевые слова: одаренные дети; дети с признаками одаренности; психологопедагогическое сопровождение одаренных детей; организация дополнительного образования детей.

\footnotetext{
${ }^{*}$ Корреспондирующий автор Адреса электронной почты: sashaum@mail.ru (С.У. Турсунбаев), evgeniya_dubchen@mail.ru (Е.A. Калина)
} 